\title{
Mauritian red nectar remains a mystery
}

Cloral nectar is rich in chemicals and F induces pollination ${ }^{1}$. Although it may be tainted by algae or mould, it usually lacks colouring agents. However, a few plant species in Mauritius break this rule and produce red nectar. We attempted to find a function for this coloration, but its role remains unclear.

In 1976, a new species of plant in the family Campanulaceae, Nesocodon mauritianus (Fig. 1a), was found in Mauritius growing on inaccessible cliffs near the huge waterfall Cascade Cinq Cents Pied ${ }^{2}$. This is the only known population and in 1997 we counted just 110-130 plants. So N. mauritianus is among the many endangered Mauritian species ${ }^{3}$. It was noted that the species' floral nectar was scarlet-red ${ }^{4}$ (Fig. 1a), an unusual characteristic that was subsequently overlooked.

We observed two bird species visiting flowers of $N$. mauritianus: the introduced red-whiskered bulbul (Pycnonotus jocosus) (Fig. 1c) and the native merle (Hypsipetes olivaceus). The bulbul pierced the base of the flower and robbed the nectar $(80.8 \%$ of 52 flower visits, 40 hours of observation of 5 flowering plants), inserted its head into the flower to reach the nectar $(9.6 \%)$ or tore the flower into pieces $(9.6 \%)$. Only one merle was observed, and it picked an entire flower and flew away with it. No other animal was seen near the plants.

We mass-propagated $N$. mauritianus through seeds and analysed its nectar. We found that the nectar's $\mathrm{pH}$ was as high as 9.2 (the known $\mathrm{pH}$ range of all species is $3-10$; ref. 1). When placed in acid, the red nectar turned yellow and showed antibacterial activity.

Using proton nuclear magnetic resonance spectroscopy, we identified the red pigment as a temperature-sensitive aurone (Fig. 1b). The yellow pigment was a lightsensitive 3-glucosylated flavone, or a flavonol with the same B-ring substitutions as the aurone. The corolla pigment was an anthocyanine with delphinidine as aglycon. All the pigments were products of flavonoid biosynthesis.

The nectar also contained 22-25\% w/w hexose-dominated sugar. No specific floral scent was noticed, but hexanal, 2-hexenal, hexenol and hexanol were identified from leaves using gas-chromatography-mass spectrometry.

We examined other Mauritian flowers for red nectar and found it in Trochetia blackburniana (a species belonging to the family Sterculiaceae). In addition, T. boutoniana was reported locally ${ }^{5}$ to produce red nectar, and this was confirmed. We measured the sugar content of the latter as
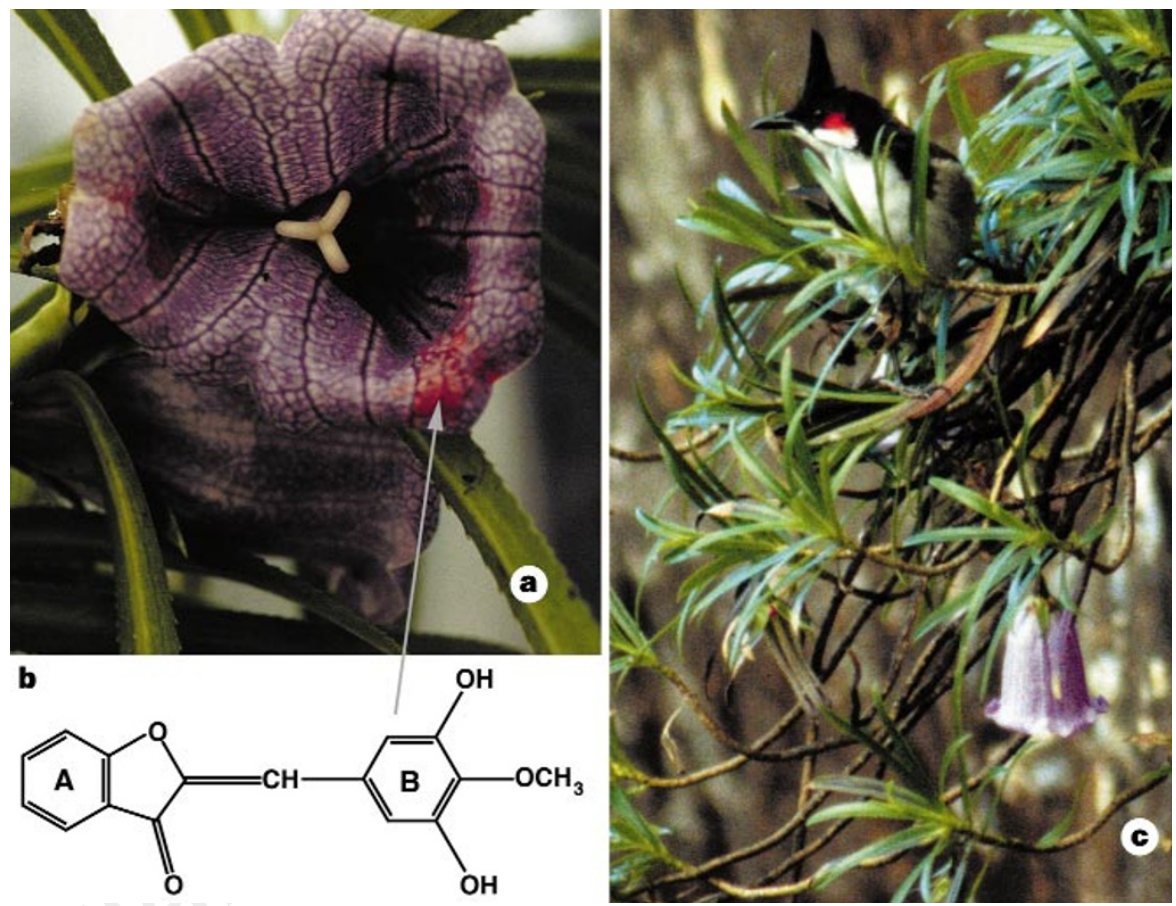

Figure 1 Red-coloured nectar in the Mauritian flower Nesocodon mauritianus. a, Red nectar flowing from a flower of $N$. mauritianus. b, Structure of the red-colouring aurone. c, N. mauritianus visited by a red-whiskered bulbul (Pycnonotus jocosus).

$25-30 \%$ and found that its red pigment was an aurone too. Trochetias are pollinated and nectar-robbed by native white-eye birds (Zosterops borbonicus and Z. chloronothos $)^{5-7}$.

These three bird-pollinated Mauritian endemics are the only known plants in the world with coloured nectar. The red nectar in the blue flower of $N$. mauritianus may improve attractiveness to birds, but why do the red-flowered Trochetias produce red nectar?

We envisage at least three explanations for the evolution of this unique character: the original pollinator was an endemic but now extinct member of the Mauritian "afterlife" (recently extinct species); the red colour is an honest signal ${ }^{9}$ to pollinators improving their foraging efficiency and generating a fitness advantage over other bird-pollinated species; or the red pigment is associated with a deterrent against nectar robbers.

We regard the last two possibilities as unlikely. If red nectar is an honest signal, then why has it failed to evolve in other regions and taxa in which bird-pollination occurs? If it is a warning, then it is a poor 'scarecrow', as these taxa are heavily robbed of nectar.

We will search for extinct pollinators among recently extinct Mauritian species. However, "ghosts are not easy to pin down"s.
Jens M. Olesen

Department of Ecology \& Genetics, Aarhus University, Ny Munkegade Building 540, DK-8000 Aarhus C, Denmark e-mail: jens.olesen@biology.aau.dk Nina Rønsted, Ulrik Tolderlund, Claus Cornett, Per Mølgaard Department of Pharmacognosy, Royal Danish School of Pharmacy, Universitetsparken 2,

DK-2100 Copenhagen Ø, Denmark Jørn Madsen

The National Encyclopedia, Nytorv 17, DK-1450 Copenhagen K, Denmark Carl G. Jones

Jersey Wildlife Preservation Trust,

Black River, Republic of Mauritius

Carl E. Olsen

Chemistry Department,

Royal Danish Veterinary and Agricultural University, Copenhagen, Thorvaldsensvej 40, DK-1870 Frederiksberg C, Denmark

1. Baker, H. G. \& Baker, I. in Coevolution of Animals and Plants (eds Gilbert, L. E. \& Raven, P. H.) 100-140 (Univ. Texas Press, Austin, 1975)

2. Richardson, I. B. K. Kew Bulletin 33, 547-550 (1979).

3. Wyse Jackson, P. S., Strahm, W., Cronk, Q. C. B. \& Parnell, J. A. N. Moorea 7, 35-45 (1988).

4. Wyse Jackson, P. S. Kew Magazine 7, 113-117 (1990). 5. Staub, F. Proc. R. Soc. Arts Sci. Mauritius 5, 7-78 (1987).

6. Safford, R. J. Dodo. J. Jersey Wildlife Preserv. Trust 27, 113-138 (1987).

Staub, F. Fauna of Mauritius and Associated Flora (Indian Ocean, Rose-Hill, 1993).

8. Lawton, J. H. Oikos 73, 145-147 (1995).

9. Zahavi, A. J. Theor. Biol. 53, 205-214 (1975). 